\title{
Perfor mance evaluation of an Organic Rankine Cycle (ORC) for power applications from low grade heat sources
}

\author{
Bernardo Peris ${ }^{*}$, a Joaquín Navarro-Esbrí ${ }^{\mathrm{a}}$, Francisco Molés ${ }^{\mathrm{a}}$, Roberto Collado ${ }^{\mathrm{b}}$, Adrián Mota- \\ Babiloni $^{\mathrm{a}, \mathrm{c}}$ \\ ${ }^{a}$ ISTENER Research Group. Department of Mechanical Engineering and Construction, Campus de Riu Sec s/n, \\ University Jaume I, E12071, Castellón, Spain. \\ ${ }^{\mathrm{b}}$ Expander-Tech, Campus de Riu Sec s/n, University Jaume I, E12071, Castellón, Spain. \\ ${ }^{\mathrm{c}}$ Institute for Industrial, Radiophysical and Environmental Safety, Camino de Vera s/n, Polytechnic University of \\ Valencia, E-46022 Valencia, Spain.
}

\begin{abstract}
In this paper the performance of an Organic Rankine Cycle (ORC) module, which was designed and built for a specific power application, is experimentally characterized. The ORC tested satisfies the main specifications for an efficient power system, highlighting a volumetric expander with large built-in volume ratio. For tests development, a monitored test bench has been used and adapted to the planned test procedure, which consisted of varying the thermal power input for different condensing conditions. Thereby, 10 steady state points are achieved and analysed according to thermal power input, gross and net electrical powers, electrical cycle efficiencies and expander effectiveness. The results show that the ORC performances are improved for higher thermal oil temperatures, capturing more thermal power, producing more electricity and achieving better cycle efficiencies. The maximum gross electrical efficiency obtained is $12.32 \%$, for a heat source temperature about $155^{\circ} \mathrm{C}$ and a direct dissipation to the ambient. Moreover, the expander reaches an electrical isentropic effectiveness about $65 \%$ for an optimum pressure ratio around 7 , being a suitable system for power applications from low grade heat sources.
\end{abstract}

Keywords Organic Rankine Cycle (ORC); power applications; test bench; heat recovery; energy efficiency.

\footnotetext{
${ }^{*}$ Corresponding Author:

Tel: +34 964728137; fax: +34 964728106.

E-mail address: bperis@uji.es
} 


\begin{tabular}{|ll|}
\hline Nomenclature & specific heat capacity $\left(\mathrm{kJ} \cdot \mathrm{kg}^{-1} \cdot \mathrm{K}^{-1}\right)$ \\
$\mathrm{c}_{\mathrm{p}}$ & enthalpy $\left(\mathrm{kJ} \cdot \mathrm{kg}^{-1}\right)$ \\
$\mathrm{h}$ & mass flow rate $\left(\mathrm{kg} \cdot \mathrm{s}^{-1}\right)$ \\
$\dot{\mathrm{m}}$ & pressure $(\mathrm{bar})$ \\
$\mathrm{P}$ & thermal power $(\mathrm{kWt})$ \\
$\mathrm{Q}$ & temperature $\left({ }^{\circ} \mathrm{C}\right)$ \\
$\mathrm{T}$ & uncertainty \\
$\mathrm{U}$ & volumetric flow rate $\left(\mathrm{m}^{3} \cdot \mathrm{s}^{-1}\right)$ \\
$\dot{\mathrm{V}}$ & electrical power $(\mathrm{kWe})$ \\
$\mathrm{W}$ & \\
Greek symbols & effectiveness $(\%)$ \\
$\varepsilon$ & efficiency $(\%)$ \\
$\eta$ & density $\left(\mathrm{kg} \cdot \mathrm{m}^{-3}\right)$ \\
$\rho$ & \\
Subscripts & expander \\
$\mathrm{e}$ & electrical \\
$\mathrm{el}$ & gross \\
$\mathrm{g}$ & heat recovery vapor generator \\
$\mathrm{HRVG}$ & isentropic \\
ise & net \\
$\mathrm{n}$ & thermal oil \\
oil & pump \\
$\mathrm{p}$ & working fluid \\
wf &
\end{tabular}

\section{Introduction}

The Organic Rankine Cycle (ORC) has been proven as an efficient way for power generation from low grade heat sources $[1$. It is a similar power cycle to the steam Rankine cycle, but uses more volatile fluids instead of water to improve the efficiency in low temperature applications [2]. Its operating principle consists of capturing the thermal energy from the heat source through the evaporation of the working fluid and reducing the enthalpy in an expander to produce mechanical work, which is turned into electricity by an electric generator. This is a closed system, which condenses the vapor from the expander outlet and pressurizes the liquid to restart the cycle again. So, it is considered a simple cycle that requires little maintenance, compared to other power cycles like Kalina [3], Goswami, transcritical cycle or trilateral-flash cycle [4]; in addition to its mature and proven technology against direct conversion techniques (thermoelectric, thermionic or piezoelectric) $[5$.

There are several low temperature applications in which the ORC can be used, like: solar thermal $[6$, geothermal $[7$, oceanic $[5$, biomass $[8$, combined heat and power $[9]$, waste heat from power plants $\left[10_{-}\right.$, waste heat from industrial processes [11] or others [12].

This wide range of possibilities has motivated researchers' efforts in order to provide suitable ORC solutions. So, various experimental studies have been carried out in the literature, as the work of Wang et al. [13] that tested a low temperature solar ORC using R245fa as working fluid 
and a rolling-piston as expander. The results showed an average shaft power output of $1.64 \mathrm{~kW}$ and an overall power generation efficiency that ranged between 3.2-4.2\%, depending on the solar collector used. Zhou et al. [14] tested an ORC using the working fluid R123 and a scroll expander, showing a maximum expander power output of $0.645 \mathrm{~kW}$ and a cycle efficiency of 8.5\%. Manolakos et al. [15] used the working fluid R134a and a scroll expander, obtained from a compressor in reverse operation, to demonstrate the technical feasibility of a low-temperature solar ORC for reverse osmosis desalination. So, the results showed net mechanical efficiencies of $0.73 \%$ and $1.17 \%$ for a cloudy and sunny day, respectively. Peterson et al. [16] used an ORC with the regenerative cycle configuration, the working fluid R123 and a scroll expander, achieving a gross cycle mechanical efficiency of $7.2 \%$ and an expander mechanical isentropic effectiveness that ranged between 45-50\%. Qiu et al. [17] experimented with a biomass-pellet boiler and an ORC for micro-CHP applications. The main working fluid used was HFE7000 and a vane type of expander. So, $0.861 \mathrm{kWe}$ were generated with a gross electrical efficiency of $1.41 \%$ and a CHP efficiency of $78.69 \%$. Declaye et al. [18] characterized an oil-free scroll expander using R245fa as working fluid, showing a maximum shaft power and mechanical efficiency of $2.1 \mathrm{~kW}$ and $8.5 \%$, respectively. Bracco et al. [19] reported that in the literature the usual expander effectiveness ranges between $60-65 \%$ with peaks of $68-70 \%$, which is in compliance with their results. The researchers tested a small-size ORC prototype using the working fluid R245fa and a scroll expander, adapted from a commercial HVAC, achieving a net cycle electrical efficiency around $8 \%$. Kane et al. [20] proposed to use two superposed ORCs, each one with an optimized working fluid and expander to overcome the limited pressure range and built-in volume ratio (Vi) of a scroll expander modified from a standard compressor. The working fluids selected were R123 for the topping ORC and R134a for the bottoming ORC. Thereby, the results showed that the superposed cycle achieved a net electrical efficiency upper $12 \%$ during tests.

As can be seen, the main expansion technology investigated for ORCs, intended for applications in low grade heat sources, is the volumetric or positive displacement machine. The reason is that volumetric expanders result more appropriate than turbo-machines, as they are characterized by lower flow rates, higher pressure ratios, much lower rotational speeds, besides to exhibit good effectiveness and tolerate liquid phase during expansion $[21$. In this way, recent works continues improving volumetric expanders, such as rotary volumetric expanders based on the Wankel concept [22 ], scroll [23] or screw expanders [24. Furthermore, an appropriate operating pressure ratio for the expander, a suitable working fluid and an efficient cycle configuration are also recommendations to increase the electrical gain $[25$.

Taking this into account, this work conducts an experimental characterization of an ORC module that satisfies the specifications for an efficient power system. Thus, it employs a volumetric expander with a large $\mathrm{Vi}$, the working fluid $\mathrm{R} 245 \mathrm{fa}$ and a regenerative cycle configuration.

For this purpose, the rest of the paper is organized as follows. Section 2 describes the test bench used. Section 3 exposes the methodology employed, pointing the measuring devices used, equations for the thermodynamic analysis and test procedure. Section 4 presents and discusses the results of the system characterization. And finally, Section 5 summarizes the main conclusions of the work.

\section{Test bench description}


In order to conduct the system performance characterization, a monitored test bench has been used and adapted to the planned operating conditions. So, the main parts of this facility are addressed.

\subsection{Heat source}

A low grade heat source has been simulated using a natural gas boiler and a thermal oil heat transfer loop, as it can be appreciated in Fig.1.a along with the ORC module and the dissipation system. The test bench allows to supply the thermal power demanded by the ORC, besides to control the test conditions. For this, it is composed of two loops. The first one is the loop of the boiler, which is automatically adjusted to the thermal power demand. The second one allows to vary the volumetric flow rate that enters in the ORC, through a pump frequency inverter, and to control the thermal oil inlet temperature in the ORC, using a three way valve and a PID controller.

The basic scheme of the facility is illustrated in Fig.1.b, whose main components are: 1-natural gas boiler, 2-ORC, 3-centrifugal pumps, 4-three way valve, 5-expansion tank, 6-main safety valve.

Fig.1. Heat source test bench: (a) general view of the facility along with the ORC module and the dissipation system, (b) basic scheme.

\subsection{Heat sink}

As usual in the case of ORC modules for power generation, the dissipation system is directly conducted through an air condenser, as also can be appreciated in Fig.1.a. This system allows to reduce exergetic losses compared to a dry cooler with cooling water, besides simplifying the scheme, since there is not required another pump nor its associated safety and control devices. The air condenser used is located above the ORC module due to space specifications in its target application [26].

The main air condenser features are listed in Table 1. As shown below, the dissipation capacity was designed for a great thermal power. This was accomplished with the purpose to maximize the final electricity produced, since a high heat exchange surface allows to reduce the fans velocity and, consequently, the electrical power consumption.

Table 1. Air condenser features.

\subsection{ORC module}

The ORC used in this work is a commercial module from Rank® [27]. This ORC uses a regenerative cycle configuration that allows not only recovering the thermal energy from the heat source, but also the waste heat from the expander outlet, improving the cycle electrical efficiency. Regarding to design issues, the module can generate up to $20 \mathrm{kWe}$ determined by the electric generator rated power. The ORC module is designed to recover about $160 \mathrm{kWt}$ of thermal power input at typical operating conditions. Moreover, the expander is designed to allow the operation along large pressure ratios, since it was developed with a built-in volume ratio of 8.0.

These and other features of the ORC module are listed in Table 2. 
Table 2. Rank® ORC module features.

\section{Methodology}

In this section the main measuring devices used for the system motoring, equations for the experimental data analysis and test procedure conducted are addressed.

\subsection{System monitoring}

Focusing on the ORC monitoring, the main parameters measured are represented in Fig.2. In the first place, the thermal power input is monitored in the hot side through inlet and outlet thermal oil temperatures, using surface thermocouples, and the thermal oil volumetric flow rate, that is measured using a vortex flow meter. From the thermal power input, the working fluid mass flow rate can be obtained through temperature and pressure conditions at the Heat Recovery Vapor Generator (HRVG) ports. So, two surface thermocouples and a single pressure transmitter are employed, neglecting the HRVG pressure drop. The pressure and temperature devices from the HRVG outlet are placed as near as possible to the expander inlet port, as well as another pressure transmitter at the expander outlet port for monitoring its performance. Furthermore, its electrical power output is measured using a wattmeter at the electric generator, while the pump electrical consumption is measured in the electric motor through another wattmeter. On the other hand, the cold side influence is simply considered with an ambient temperature device with the purpose to obtain objective and comparable net powers.

Fig.2. Regenerative ORC scheme and main parameters monitored.

The measuring devices uncertainties, extracted from manufacturers' data sheets, and the calculated parameters uncertainties $U_{y}$, obtained as a function of the uncertainty on each measured variable $U_{x_{i}}$ by Eq. (1) $[28$, are collected in Table 3 .

$$
U_{y}=\sqrt{\sum_{i=1}^{N}\left(\frac{\partial y}{\partial x_{i}}\right)^{2} \cdot U_{x_{i}}^{2}}
$$

Table 3. Uncertainties of measured and calculated parameters.

\subsection{Ther modynamic analysis equations}

For the analysis of the experimental data obtained during tests various equations have been used. Firstly, the thermal power input is calculated through Eq. (2) and the thermal oil properties at the operating conditions. From this, the working fluid mass flow rate can be obtained by Eq. (3). The working fluid properties have been evaluated using software REFPROP [29].

$$
\begin{aligned}
& Q_{\text {in }}=\rho_{\text {oil }, \text { out }} \cdot \dot{V}_{\text {oil, out }} \cdot c_{\text {poil }} \cdot\left(T_{\text {oil ,in }}-T_{\text {oil out }}\right) \\
& \dot{m}_{w f}=\frac{Q_{\text {in }}}{h_{e, \text { in }}-h_{H R V G, \text { in }}}
\end{aligned}
$$


The gross electrical power from the electric generator is directly measured, as well as the electrical pump consumption and, therefore, it can be calculated the net power output generated using Eq. (4). The cycle efficiency is obtained using the gross electrical efficiency by Eq. (5) and net electrical efficiency by Eq. (6). The performance ratio of the expander can be defined as the electrical isentropic effectiveness by Eq. (7), often also named expander overall efficiency. This equation expresses the relationship between the electrical power measured in the electric generator and the maximum that could be ideally obtained.

$$
\begin{aligned}
& W_{n}=W_{g}-W_{p} \\
& \eta_{g}=\frac{W_{g}}{Q_{i n}} \\
& \eta_{n}=\frac{W_{n}}{Q_{i n}} \\
& \varepsilon_{e l, i s e}=\frac{W_{g}}{\dot{m}_{w f} \cdot\left(h_{e, \text { in }}-h_{e, \text { out }, \text { ise }}\right)}
\end{aligned}
$$

Other parameters calculated and used for the analysis are the pressure ratio in the expander, defined by Eq. (8), and Carnot efficiency, as Eq. (9) with temperatures in Kelvin units.

$$
\begin{aligned}
& \text { pressureratio }=\frac{P_{e, \text { in }}}{P_{e, \text { out }}} \\
& \text { Carnot efficiency }=1-\frac{T_{\text {ambient }}}{T_{\text {oil }, \text { in }}}
\end{aligned}
$$

\subsection{Test procedure}

The ORC module was tested varying the thermal oil inlet temperature, obtaining thermal power inputs from partial loads up to near design rated values. For this, the control of the thermal oil volumetric flow rate was imposed with a fixed frequency set point in the pump inverter. On the other hand, the ambient temperature cannot be controlled, however different operating conditions have been achieved during tests.

As a result, 10 steady state points were achieved. These steady state points were obtained with a stationary stability in a fluctuation range lower than $1 \%$ on each variable for at least 10 minutes. In Table 4 it can be seen the operating range obtained during tests for each variable.

Table 4. Operating range of each variable during tests.

\section{Results and discussions}

From the experimental data obtained during tests an analysis has been conducted, whose results are exposed and discussed in this section. 
In a first step, the thermal power characterization is addressed. Fig. 3.a shows that higher thermal oil temperatures allow higher thermal power captures by the ORC. This is due to the control conducted by ORC. So, when the thermal oil temperature raises, also the working fluid temperature increases, as Fig. 3.b shows. The control of the ORC takes into account this change and maintains a superheating degree within a permissible operating range. So, for higher temperatures the pressure of the cycle increases, as can be seen in Fig. 3.c, which corresponds to a higher working fluid mass flow rate, as Fig. 3.d shows.

Fig.3. Thermal power characterization: (a) thermal oil inlet temperature, (b) expander inlet temperature, (c) expander inlet pressure, (d) working fluid mass flow rate.

When the system captures more thermal power, in this case due to a rise of the thermal oil temperature, the electrical generation also increases, as Fig. 4.a shows. This is also related to the pressure ratio, as Fig. 4.b represents. Similarly, Fig. 4.c and Fig.4.d show that the net electrical power also increases with the thermal power input and larger pressure ratios.

Fig.4. Electrical power characterization: (a) gross electricity with thermal input, (b) gross electricity with pressure ratio, (c) net electricity with thermal input, (d) net electricity with pressure ratio.

Regarding to efficiencies, Fig.5.a represents the gross electrical efficiency of the cycle. It is observed that the efficiency tendency grows with the pressure ratio up to a maximum of $12.32 \%$, a value that could have been even greater for higher thermal oil temperatures. If the net electrical efficiency is compared to the ideally Carnot efficiency in Fig. 5.b, it can be observed that the cycle efficiency tendency appears to be attenuated for the highest values. This effect can be justified observing Fig. 5.c referred to the expander. So, the electrical isentropic effectiveness of the expander is maximized above $65 \%$ for a pressure ratio around 7 , imposed by the expander $\mathrm{Vi}$, that is a suitable operating range for a power application from low grade heat sources. This figure also shows the energy losses produced when the expander operates in under-expansion and, still more, in over-expansion. Other energy losses that contribute to draw this curve are heat losses during expansion, frictions, supply pressure drop, internal leakages [30 , or the alternator electrical efficiency operating at partial loads [31]. Furthermore, if the gross electrical efficiency of the cycle is compared with the expander electrical isentropic effectiveness, as Fig. 5.d shows, it can be noted that operating with a moderate under-expansion the cycle efficiency can be improved, similar as the results of Declaye et al. [18. Although an excessive under-expansion could deteriorate the cycle efficiency, as reported Bracco et al. [19.

Fig.5. Thermodynamic efficiencies characterization: (a) gross, (b) net, (c) expander, (d) cycle.

\section{Conclusions}

This work has characterized the performance of an ORC module in a test bench, varying the thermal power input up to near design rated values and dissipating directly to the ambient. So, 10 steady state points have been achieved and analysed.

Thereby, the results show that, for a given ORC module, a higher thermal oil inlet temperature allows higher thermal power captures by the ORC. This implies a higher temperature, pressure and working fluid mass flow rate in the system. Therefore, the gross and net electrical powers increase. Moreover, it has been demonstrated the direct influence of the expander on the cycle 
performances. So, the maximum electrical efficiency appears when the optimum pressure ratio of the expander, imposed by the $\mathrm{Vi}$, is overcome, operating with a moderate under expansion.

Regarding to experimental data summary, the thermal power input ranged from $95.14 \mathrm{kWt}$ to $146.41 \mathrm{kWt}$. The maximum gross and net electrical powers achieved are $18.03 \mathrm{kWe}$ and 15.93 $\mathrm{kWe}$, respectively. The maximum cycle efficiencies reached are a gross electrical efficiency of $12.32 \%$ and a net electrical efficiency of $10.88 \%$. Moreover, the expander achieved a maximum electrical isentropic effectiveness of $65.33 \%$ for an optimum pressure ratio around 7 , imposed by the expander $\mathrm{Vi}$, which is a suitable value for power applications from low grade heat sources.

\section{Acknowledgements}

The authors are indebted to the Minister of industry of 'Generalitat Valenciana' (Spain) for its financial assistance under project INIDIV2010022 and Rank ${ }^{\circledR}$, the ORC manufacturer, for its support in this project. Also to thank greatly the Jaume I University for its financial support under the $\mathrm{PhD}$ grant PREDOC/2013/28 of 'Convocatòria d'ajudes predoctorals per a la formació de personal investigador del Pla de promoció de la investigació de la Universitat Jaume I de Castelló (Spain)'.

\section{References}

[1] Ziviani D, Beyene A, Venturini M. Advances and challenges in ORC systems modeling for low grade thermal energy recovery. Applied Energy 2014; 121: 79-95.

[2] Li J, Pei G, Li Y, Wang D, Ji J. Energetic and exergetic investigation of an organic Rankine cycle at different heat source temperatures. Energy 2012; 38: 85-95.

[3] Bombarda P, Invernizzi $\mathrm{CM}$, Pietra C. Heat recovery from Diesel engines: A thermodynamic comparison between Kalina and ORC cycles. Applied Thermal Engineering 2010; 30: 212-219.

[4] Chen H, Goswami DY, Stefanakos EK. A review of thermodynamic cycles and working tluids for the conversion of low-grade heat. Renewable and Sustainable Energy Reviews 2010; 14: 3059-3067.

[5] Tchanche BF, Lambrinos Gr, Frangoudakis A, Papadakis G. Low grade heat conversion into power using organic Rankine cycles - A review of various applications. Renewable and Sustainable Energy Reviews 2011; 15: 3963-3979.

[6] Wang M, Wang J, Zhao Y, Zhao P, Dai Y. 'Thermodynamic analysis and optimization of a solar-driven regeneratıve organic Rankine cycle (URC) based on tlat-plate solar collectors. Applied Thermal Engineering 2013; 50: 816-825.

[7] Liu X, Wang X, Zhang C. Sensitivity analysis of system parameters on the performance of the Organic Rankine Cycle system for binary-cycle geothermal power plants. Applied Thermal Engineering 2014; 71: 175-183. 
[8] Huang Y, Mcllveen-Wright DR, Rezvani S, Huang MJ, Wang YD, Roskilly AP, Hewitt NJ. Comparative techno-economic analysis of biomass fuelled combined heat and power for commercial buildings. Applied Energy 2013; 112: 518-525.

[9] Farrokhi M, Noie SH, Akbarzadeh AA. Preliminary experimental investigation of a natural gas-fired ORC-based micro-CHP system for residential buildings. Applied Thermal Engineering 2014; 69: 221-229.

[10] Dolz V, Novella R, García A, Sánchez J. HD Diesel engine equipped with a bottoming Rankine cycle as a waste heat recovery system. Part 1: Study and analysis of the waste heat energy. Applied Thermal Engineering 2012; 36: 269-278.

[11] Kwak DH, Binns M, Kim JK. Integrated design and optimization of technologies for utilizing low grade heat in process industries. Applied Energy 2014: 131; 307-322.

[12] Al-Weshahi MA, Anderson A, Tian G. Organic Rankine Cycle recovering stage heat from MSF desalination distillate water. Applied Energy 2014; 130: 738-747.

[13] Wang XD, Zhao L, Wang JL, Zhang WZ, Zhao XZ, Wu W. Performance evaluation of a low-temperature solar Rankine cycle system utilizing R245fa. Solar Energy 2010; 84: 353-364.

[14] Zhou N, Wang X, Chen Z, Wang Z. Experimental study on Organic Rankine Cycle for waste heat recovery from low-temperature tlue gas. Energy 2013; 55: 216-225.

[15] Manolakos D, Kosmadakis G, Kyritsi S, Papadakis G. On site experimental evaluation of a low-temperature solar organic Rankine cycle system for RO desalination. Solar Energy 2009; 83: 646-656.

[16] Peterson RB, Wang H, Herron T. Performance of small-scale regenerative Rankine power cycle employing a scroll expander. Proceedings of the Institution of Mechanical Engineers, Part A: Journal of Power and Energy 2008; 222: 271-282.

[17] Qiu G, Shao Y, Li J, Liu H, Riffat SB. Experimental investigation of a biomass-fired ORCbased micro-CHP for domestic applications. Fuel 2012; 96: 374-382.

[18] Declaye S, Quoilin S, Guillaume L, Lemort V. Experimental study on an open-drive scroll expander integrated into an ORC (Organic Rankine Cycle) system with R245ta as working tluid. Energy 2013; 55: 173-183.

[19] Bracco R, Clemente S, Micheli D, Reini M. Experimental tests and modelization of a domestic-scale ORC (Organic Rankine Cycle). Energy 2013; 58: 107-116.

[20] Kane M, Larrain D, Favrat D, Allani Y. Small hybrid solar power system. Energy 2003; 28: $1427-1443$.

[21] Quoilin S, Van Den Broek M, Declaye S, Dewallet P, Lemort V. Techno-economic survey of Urganic Rankine ('ycle (UKC) systems. Renewable and Sustainable Energy Reviews 2013; 22: $168-186$. 
[22] Antonelli M, Baccioli A, Francesconi M, Desideri U, Martorano L. Operating maps of a rotary engine used as an expander for micro-generation with various working fluids. Applied Energy 2014; 113: 742-750.

[23] Song P, Wei M, Shi L, Danish SN, Ma C. A review of scroll expanders for organic Rankine cycle systems. Applied Thermal Engineering 2014; 1-11. http://dx.doi.org/10.1016/j.applthermaleng.2014.05.094.

[24] Zhu Y, Jiang L, Jin V, Yu L. Impact of built-in and actual expansion ratio difference of expander on ORC system performance. Applied Thermal Engineering 2014; 71: 548-558.

[25] Peris B, Navarro-Esbrí J, Molés F. Bottoming organic Rankine cycle contigurations to increase Internal Combustion Engines power output from cooling water waste heat recovery. Applied Thermal Engineering 2013; 61:364-371.

[26] Navarro-Esbrí J, Peris B, Collado R, Molés F. Micro-generation and micro combined heat and power generation using "free" low temperature heat sources through Organic Rankine Cycles. International Conference on Renewable Energies and Power Quality. Bilbao (Spain); 2013.

[27] Rank®. Castellon, Spain. Available from: <www.rankweb.es> [accessed 29.07.14].

[28] Lemort V, Quoilin S, Cuevas C, Lebrun J. Testing and modeling a scroll expander integrated into an Organic Rankine Cycle. Applied Thermal Engineering 2009; 29: 3094-3102.

[29] Lemmon E, Huber M, McLinden M. NIST REFPROP standard reference database 23. Version 8.0. User's guide. NIST; 2007.

[30] Ibarra M, Rovira A, Alarcón-Padilla DC, Blanco J. Performance of a $5 \mathrm{kWe}$ Organic Rankine Cycle at part-load operation. Applied Energy 2014; 120: 147-158.

[31] Erhart T, Eicker U, Infield D. Part-load characteristics of Organic-Rankine-Cycles. 2nd European Conference on Polygeneration. Tarragona, Spain; 2011. 


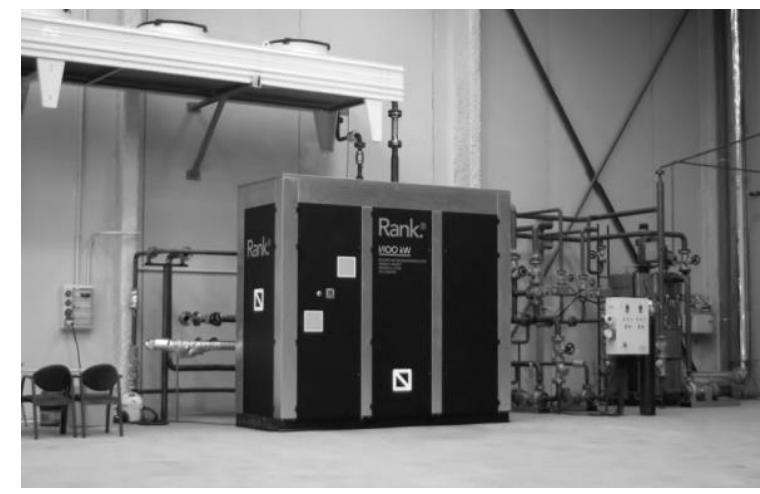

(a)



(b)

Fig.1. Heat source test bench: (a) general view of the facility along with the ORC module and the dissipation system, (b) basic scheme. 




Fig.2. Regenerative ORC scheme and main parameters monitored. 




(a)

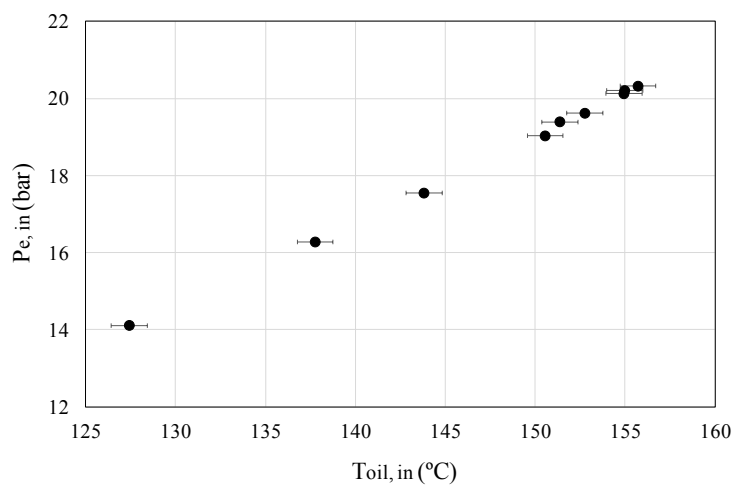

(c)

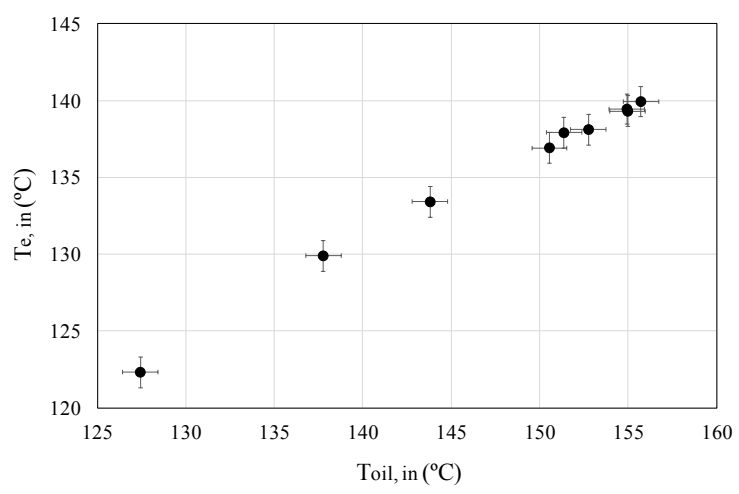

(b)

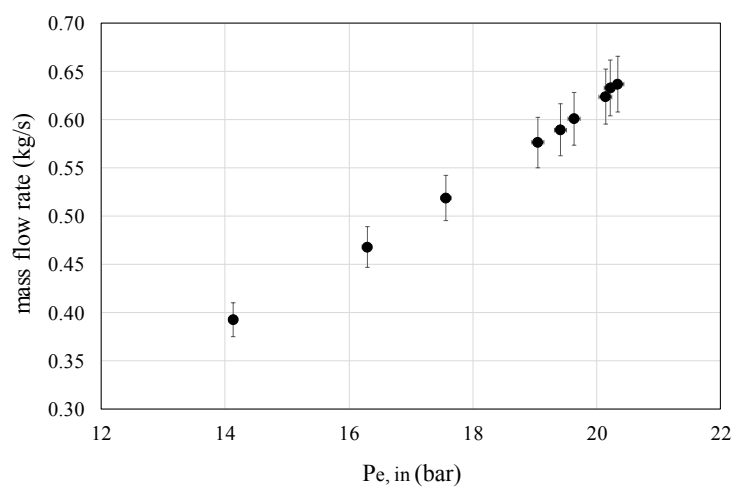

(d)

Fig.3. Thermal power characterization: (a) thermal oil inlet temperature, (b) expander inlet temperature, (c) expander inlet pressure, (d) working fluid mass flow rate. 


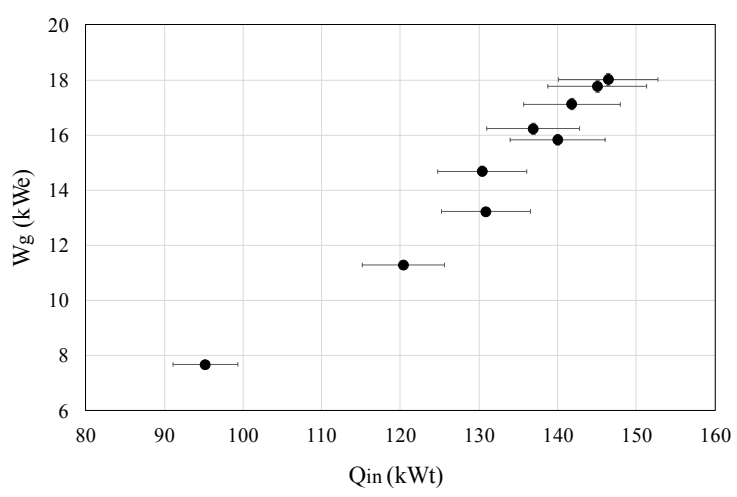

(a)

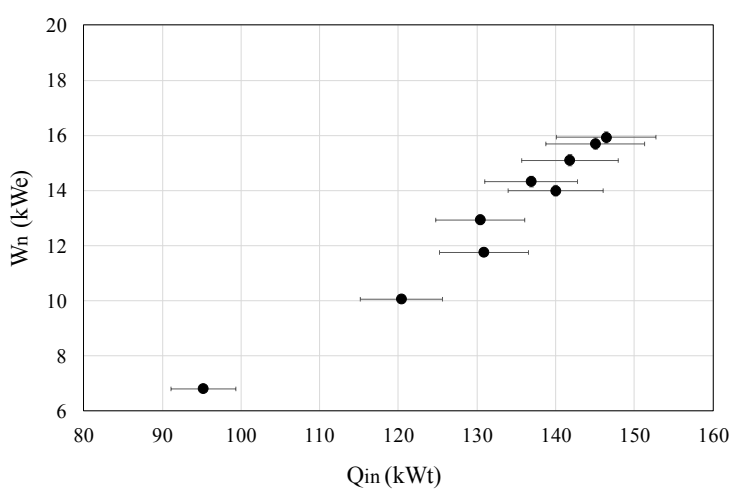

(c)

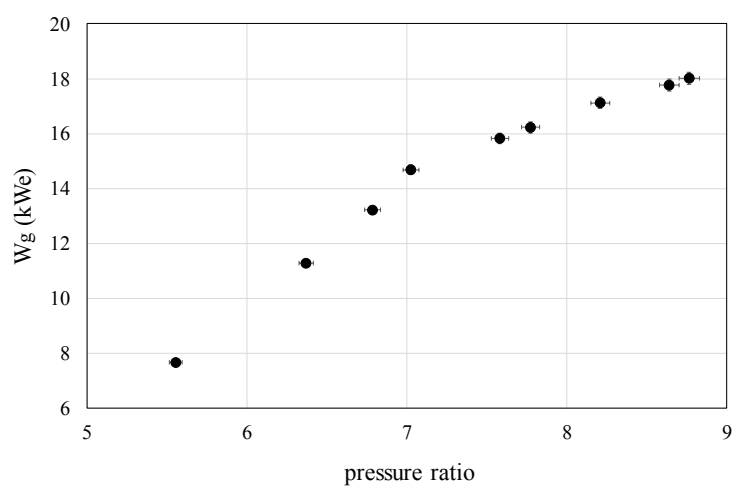

(b)

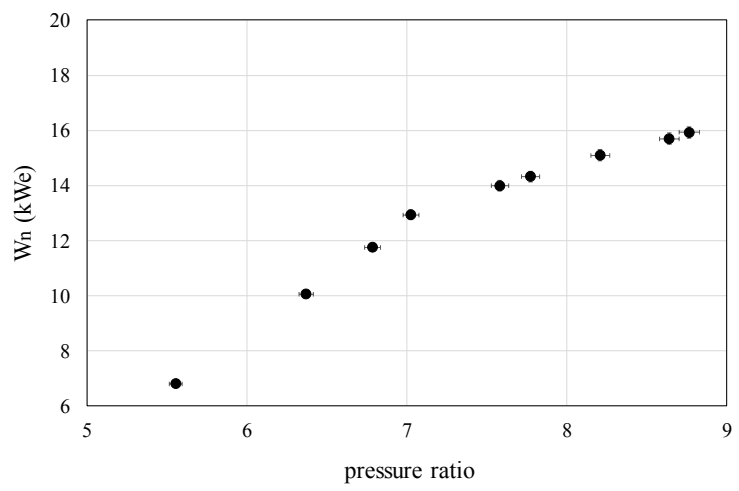

(d)

Fig.4. Electrical power characterization: (a) gross electricity with thermal input, (b) gross electricity with pressure ratio, (c) net electricity with thermal input, (d) net electricity with pressure ratio. 


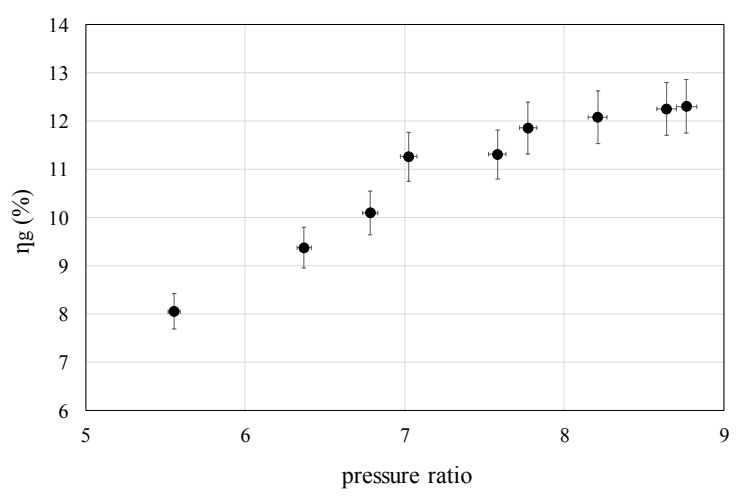

(a)

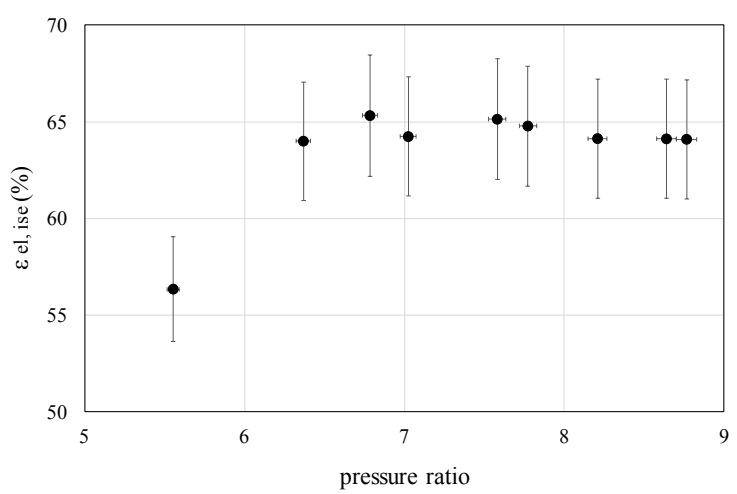

(c)

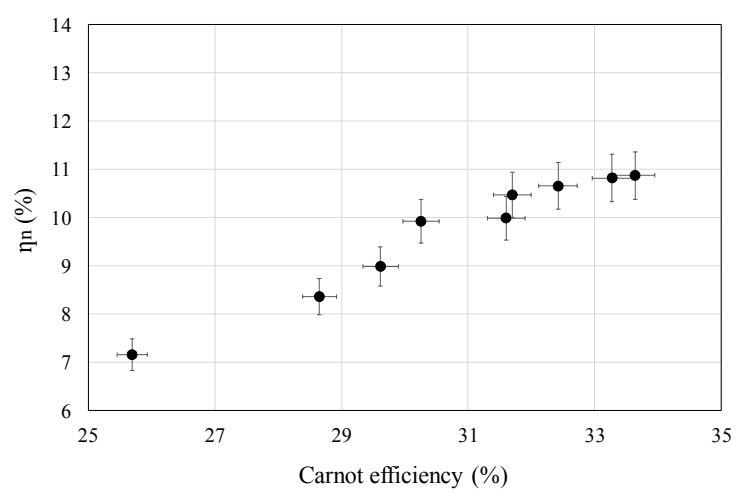

(b)

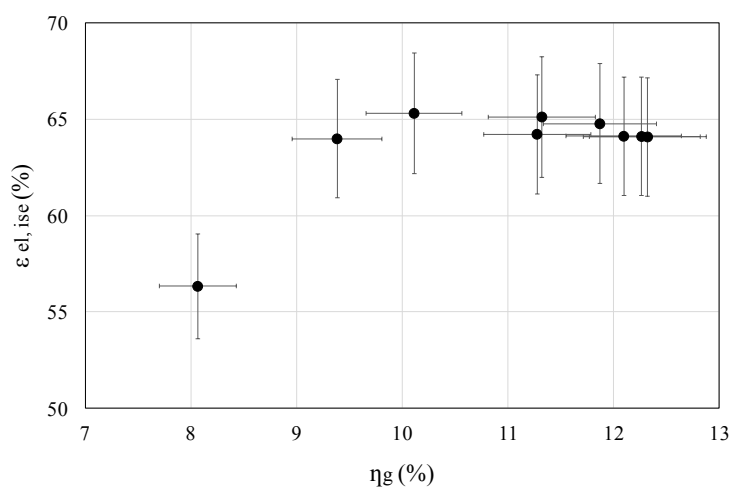

(d)

Fig.5. Thermodynamic efficiencies characterization: (a) gross, (b) net, (c) expander, (d) cycle. 


\section{Figure captions}

Fig.1. Heat source test bench: (a) general view of the facility along with the ORC module and the dissipation system, (b) basic scheme.

Fig.2. Regenerative ORC scheme and main parameters monitored.

Fig.3. Thermal power characterization: (a) thermal oil inlet temperature, (b) expander inlet temperature, (c) expander inlet pressure, (d) working fluid mass flow rate.

Fig.4. Electrical power characterization: (a) gross electricity with thermal input, (b) gross electricity with pressure ratio, (c) net electricity with thermal input, (d) net electricity with pressure ratio.

Fig.5. Thermodynamic efficiencies characterization: (a) gross, (b) net, (c) expander, (d) cycle. 
Table 1. Air condenser features.

\begin{tabular}{lr}
\hline Dissipation capacity $(\mathrm{kWt})$ & 157.90 \\
Air volumetric flow rate $\left(\mathrm{m}^{3} \cdot \mathrm{h}^{-1}\right)$ & 65,500 \\
Number of fan units & 5 \\
Energy efficiency class & A \\
Maximum consumption at full load $(\mathrm{kWe})$ & 2.19 \\
Surface $\left(\mathrm{m}^{2}\right)$ & $1,112.9$ \\
\hline
\end{tabular}


Table 2. Rank® ORC module features.

\begin{tabular}{lr}
\hline Alternator rated power $(\mathrm{kWe})$ & 20 \\
Rated thermal power input $(\mathrm{kWt})$ & 160 \\
ORC configuration & regenerative \\
Working fluid & $\mathrm{R} 245 \mathrm{fa}$ \\
Expander technology & volumetric \\
Built-in volume ratio & 8.0 \\
Heat exchangers type & brazed plate \\
Maximum activation temperature $\left({ }^{\circ} \mathrm{C}\right)$ & 170 \\
Minimum activation temperature $\left({ }^{\circ} \mathrm{C}\right)$ & 120 \\
\hline
\end{tabular}


Table 3. Uncertainties of measured and calculated parameters.

\begin{tabular}{lr}
\hline Parameter & $\mathrm{U}$ \\
\hline Temperature $\left({ }^{\circ} \mathrm{C}\right)$ & \pm 1 \\
Pressure (\%) & 0.5 \\
Thermal oil volumetric flow rate (\%) & 0.75 \\
Electrical power (\%) & 1.20 \\
\hline Thermal power input (\%) & 4.33 \\
Working fluid mass flow rate (\%) & 4.54 \\
Net electrical power (\%) & 1.37 \\
Gross cycle electrical efficiency (\%) & 4.50 \\
Net cycle electrical efficiency (\%) & 4.55 \\
Electrical isentropic effectiveness (\%) & 4.89 \\
Pressure ratio (\%) & 0.71 \\
Carnot efficiency (\%) & 0.94 \\
\hline
\end{tabular}


Table 4. Operating range of each variable during tests.

\begin{tabular}{lr}
\hline Parameter & Operating range \\
\hline $\mathrm{T}_{\text {oil in in }}\left({ }^{\circ} \mathrm{C}\right)$ & $127.40-155.98$ \\
$\mathrm{~T}_{\text {oil, out }}\left({ }^{\circ} \mathrm{C}\right)$ & $104.60-118.04$ \\
$\dot{\mathrm{V}}_{\text {oil }}\left(\mathrm{m}^{3} \cdot \mathrm{s}^{-1}\right)$ & $2.01 \mathrm{E}-3-2.10 \mathrm{E}-3$ \\
$\mathrm{~T}_{\text {ambient }}\left({ }^{\circ} \mathrm{C}\right)$ & $11.48-24.52$ \\
$\mathrm{P}_{\mathrm{e}, \text { in }}(\mathrm{bar})$ & $14.12-20.40$ \\
$\mathrm{P}_{\mathrm{e}, \text { out }}(\mathrm{bar})$ & $2.32-2.71$ \\
$\mathrm{~T}_{\mathrm{e}, \text { in }}\left({ }^{\circ} \mathrm{C}\right)$ & $122.35-140.12$ \\
$\mathrm{~T}_{\mathrm{HRVG}, \text { in }}\left({ }^{\circ} \mathrm{C}\right)$ & $41.65-66.95$ \\
$\mathrm{~W}_{\mathrm{g}}(\mathrm{kWe})$ & $7.67-18.03$ \\
$\mathrm{~W}_{\mathrm{p}}(\mathrm{kWe})$ & $0.85-2.10$ \\
\hline
\end{tabular}

